\title{
Effects of Low-Fat High-Fibre Diet and Mitratapide on Body Weight Reduction, Blood Pressure and Metabolic Parameters in Obese Dogs
}

\author{
Cristina PEÑA ${ }^{1)}$, Lourdes SUAREZ1), Inmaculada BAUTISTA-CASTAÑO2), M. Candelaria JUSTE ${ }^{1)}$, \\ Elena CARRETÓN ${ }^{1)}$ and José Alberto MONTOYA-ALONSO ${ }^{1) *}$ \\ 1) Veterinary Medicine Service, Faculty of Veterinary Medicine, University of Las Palmas de Gran Canaria, Las Palmas, Spain \\ 2) Department of Clinical Sciences, Faculty of Medicine, University of Las Palmas de Gran Canaria, Las Palmas, Spain
}

(Received 27 September 2013/Accepted 23 May 2014/Published online in J-STAGE 11 June 2014)

\begin{abstract}
The aim of the present study was to compare the impact on blood pressure and different metabolic parameters of a weight-loss program on obese dogs fed on a low-fat high-fibre diet and treated with and without mitratapide. The study sample consisted of 36 obese dogs, randomly assigned to a control group $(n=17)$, which were fed on a low-fat high-fibre diet, and an intervention group ( $\mathrm{n}=19)$, fed on the same diet and treated with mitratapide. Variables measured included body condition score, body weight, heart rate, systolic and diastolic blood pressures; total cholesterol, triglycerides and glucose levels; alanine aminotransferase and alkaline phosphatase activity, measured both at baseline (day 0) and at the end of the weight loss program (day 85). All the studied parameters had decreased in both groups at the end of the study; these being diastolic blood pressure, total cholesterol and alanine aminotransferase, significantly lower in dogs treated with mitratapide. The use of mitrapide in addition to low-fat high-fibre diet does not seem to offer any further useful effect in the loss of weight during the treatment of canine obesity. On the other hand, mitratapide seems to present certain beneficial effects on pathologies associated with obesity, these being mainly related to blood pressure, lipids and hepatic parameters.

KEY WORDS: canine, hyperlipidaemia, hypertension, mitratapide, obesity
\end{abstract}

doi: 10.1292/jvms.13-0475; J. Vet. Med. Sci. 76(9): 1305-1308, 2014

Obesity is the most common nutritional disease in dogs with an estimated prevalence of canine overweight and obesity between $10 \%$ and $44 \%$ in first world countries $[2,6,7$, $15,18]$ and following the same rising trend as human obesity [26]. Positive energy balance is related to obesity, but several factors can contribute to the development of canine obesity, such as sedentary lifestyle, owners' preferences, genetics or neutered animals [7, 10, 25].

Obesity is known to predispose a high number of serious medical conditions including hypertension, cardiorespiratory disorders, abnormalities in circulating lipid profiles, diabetes mellitus and other chronic health problem, as well as detrimental effects on the longevity of dogs, and therefore, an adequate control of associated morbidity is fundamental for the treatment of canine obesity $[10,20]$. In humans, numerous studies have shown the benefit of weight loss, and even small losses of weight have demonstrated a clear health benefit [19]. However, the studies related to health benefits associated with loss of weight in dog are rather limited.

Management of canine obesity through dietary restriction and increased physical activity is often difficult to achieve and dependent upon the motivation of the owner. However, with the development of mitratapide and dirlotapide, micro-

*Correspondence to: Montoya-Alonso, J. A., Veterinary Medicine Service, Faculty of Veterinary Medicine, University of Las Palmas de Gran Canaria, 35413-Arucas (Las Palmas), Spain. e-mail: amontoya@dpat.ulpgc.es

\section{(C)2014 The Japanese Society of Veterinary Science}

This is an open-access article distributed under the terms of the Creative Commons Attribution Non-Commercial No Derivatives (by-nc-nd) License $<$ http://creativecommons.org/licenses/by-nc-nd/3.0/>. somal triglyceride transfer protein inhibitors for canine use, the veterinarian has a supplementary method to widen the traditional weight control programmes $[11,12,28]$. Mitratapide works by blocking the microsomal triglyceride transfer protein that is involved in the absorption of dietary lipids and consequently reduces the absorption of these lipids, resulting in a decrease of the total energy intake; besides, lipids retained in the enterocytes are also believed to cause the release into the circulation of gastrointestinal peptides associated with satiety, triggering a decreased appetite [11, 27]. This approach has the additional advantage that weight loss is achieved without significant dietary restriction or change in exercise regimen, providing encouragement for the owner to comply with subsequent dietary and exercise recommendations, thereby increasing the likelihood for long-term success [13]. Although loss of weight by reduction in food intake, or by treatment with oral mitratapide or dirlotapide has been reported in interventional studies [9, 11, 12], there is limited information on the changes in the morbidities associated to obesity during weight loss in canine population using these medicinal products [9].

The aim of the study was to assess the effects of a program of loss of weight in obese dogs, treated with mitratapide and a high fibre dry diet, and the impact on blood pressure and some metabolic parameters [alanine aminotransferase (ALT), alkaline phosphatase (ALP), total cholesterol (CLT), triglycerides and glucose].

The study sample consisted of 36 urban household overweight dogs (83.3\% females and $16.7 \%$ males), which visited several veterinary centers for routine consultations. Included animals were apparently healthy dogs after being ruled out metabolic underlying conditions which could be 
Table 1. Mean blood pressure, heart rate and plasma levels of the measured metabolic parameters in group a (dogs fed with low-fat high-fibre diet) and group B (dogs fed with low-fat high-fibre diet and treated with mitratapide oral solution), at the beginning of the treatment (day 0 ) and at the end of the treatment (day 85)

\begin{tabular}{|c|c|c|c|c|c|c|c|}
\hline \multirow[t]{2}{*}{ Measured parameters } & & Day 0 & Day 85 & \multirow[t]{2}{*}{$P$-value ${ }^{\text {a) }}$} & \multirow{2}{*}{$\begin{array}{l}\text { Percentage of } \\
\text { reduction } \\
\text { Mean } \pm \mathrm{SD}\end{array}$} & \multirow{2}{*}{$\begin{array}{l}\text { Difference inter } \\
\text { individual } \\
\text { Mean } \pm \mathrm{SD}\end{array}$} & \multirow[t]{2}{*}{$P$-value ${ }^{\mathrm{b})}$} \\
\hline & & Mean \pm SD & Mean \pm SD & & & & \\
\hline \multirow[t]{2}{*}{ Weight (kg) } & Diet & $19.0 \pm 11.8$ & $15.8 \pm 9.5$ & & $-16.8 \pm 8.0 \%$ & & \\
\hline & Diet+Mitratapide & $15.8 \pm 9.5$ & $13.5 \pm 8.9$ & NS & $-16.1 \pm 5.6 \%$ & $2.5 \pm 1.1$ & $P<0.001$ \\
\hline \multirow{2}{*}{$\begin{array}{l}\text { Systolic blood } \\
\text { pressure (mm Hg) }\end{array}$} & Diet & $172.6 \pm 16.2$ & $145.4 \pm 18.2$ & & $-15.6 \pm 8.0 \%$ & & \\
\hline & Diet+Mitratapide & $170.2 \pm 9.7$ & $140.0 \pm 10.7$ & NS & $-17.4 \pm 8.1 \%$ & $28.7 \pm 14.3$ & $P<0.001$ \\
\hline \multirow{2}{*}{$\begin{array}{l}\text { Diastolic blood pressure } \\
(\mathrm{mm} \mathrm{Hg})\end{array}$} & Diet & $113.1 \pm 13.6$ & $93.6 \pm 9.2$ & & $-16.3 \pm 11.0 \%$ & & \\
\hline & Diet+Mitratapide & $122.8 \pm 6.5$ & $89.2 \pm 9.8$ & $P<0.001$ & $-27.2 \pm 7.8 \%$ & $26.9 \pm 13.9$ & $P<0.001$ \\
\hline \multirow[t]{2}{*}{ Heart rate (BPM) } & Diet & $132.7 \pm 17.8$ & $118.9 \pm 16.4$ & & $-10.1 \pm 7.1 \%$ & & \\
\hline & Diet+Mitratapide & $133.9 \pm 22.8$ & $114.5 \pm 16.3$ & NS & $-13.8 \pm 7.1 \%$ & $16.7 \pm 11.2$ & $P<0.001$ \\
\hline \multirow{2}{*}{$\begin{array}{l}\text { Total cholesterol } \\
(\mathrm{mg} / \mathrm{d} l)\end{array}$} & Diet & $309.1 \pm 44.9$ & $248.4 \pm 41.9$ & & $-18.4 \pm 15.8 \%$ & & \\
\hline & Diet + Mitratapide & $345.3 \pm 36.7$ & $244.3 \pm 44.5$ & $P=0.027$ & $-28.7 \pm 13.5 \%$ & $82.0 \pm 55.5$ & $P<0.001$ \\
\hline \multirow[t]{2}{*}{ Triglycerides (mg/ d $l$ ) } & Diet & $411.5 \pm 55.0$ & $297.8 \pm 46.7$ & & $-26.7 \pm 12.5 \%$ & & \\
\hline & Diet + Mitratapide & $412.0 \pm 56.6$ & $278.0 \pm 44.4$ & NS & $-32.1 \pm 9.2 \%$ & $124.4 \pm 54.1$ & $P<0.001$ \\
\hline \multirow[t]{2}{*}{ Glucose (mg/ dl) } & Diet & $124.8 \pm 18.4$ & $101.7 \pm 11.6$ & & $-16.5 \pm 17.1 \%$ & & \\
\hline & Diet+Mitratapide & $125.4 \pm 20.1$ & $98.6 \pm 10.4$ & NS & $-19.0 \pm 17.1 \%$ & $25.0 \pm 24.6$ & $P<0.001$ \\
\hline \multirow{2}{*}{$\begin{array}{l}\text { Alanine aminotransferase } \\
(\mathrm{ALT})(\mathrm{U} / l)\end{array}$} & Diet & $117.2 \pm 21.6$ & $101.1 \pm 21.2$ & & $-13.0 \pm 13.3 \%$ & & \\
\hline & Diet+Mitratapide & $127.3 \pm 26.9$ & $93.6 \pm 20.4$ & $P=0.014$ & $-25.1 \pm 13.0 \%$ & $25.3 \pm 21.9$ & $P<0.001$ \\
\hline \multirow{2}{*}{$\begin{array}{l}\text { Alkaline phosphatase } \\
(\text { ALP) }(\mathrm{U} / l)\end{array}$} & Diet & $252.0 \pm 79.4$ & $188.5 \pm 56.4$ & & $-20.6 \pm 24.8 \%$ & & \\
\hline & Diet + Mitratapide & $277.0 \pm 107.6$ & $189.3 \pm 65.5$ & NS & $-29.2 \pm 15.8 \%$ & $76.3 \pm 74.3$ & $P<0.001$ \\
\hline
\end{tabular}

"Percentage of reduction" refers to percentage of decrease of the parameter on day 85 compared to day 0 . SD: standart deviation; NS: no significative; a) $P$-value from Student's-test for independent samples, b) $P$-value from Student's-test for related samples.

related to obesity (hypothyroidism, hyperadrenocorticism and diabetes mellitus); all the owners consented to participate in this study. The age range was between 6 and 14 years (mean $9.5 \pm 1.9$ years); the studied group consisted of 21 mixed-breed dogs, 7 poodles, 5 cocker spaniels and 3 golden retrievers. The weight status of the dogs was determined by body condition score (BCS) always assessed by the same veterinarian, using a 9-point scale [16]; all the dogs were obese (BCS 8 or 9). The study was performed in accordance with ethical principles and in accordance with the current European legislation on animal protection.

The dogs were by simple randomization divided into 2 groups. Group A consisted of 17 dogs used as a control group, whereas group B consisted of 19 dogs which received mitratapide oral solution (Yarvitan ${ }^{\circledR}$, Janssen Pharmaceutica NV, Beerse, Belgium) at the therapeutic daily dose of $0.63 \mathrm{mg} / \mathrm{kg}$. The dogs were treated once daily for 2 times 21 consecutive days with an intermediate period of 14 consecutive days without treatment. All 36 dogs were only fed with a low-fat high-fibre commercial prescription diet (Hill's R/D ${ }^{\circledR}$, Hill's Pet Nutrition Inc., Topeka, KS, U.S.A.). The used diet was mainly composed of $34.6 \%$ protein, $8.2 \%$ fat, $38.2 \%$ carbohydrate (nitrogen-free extract) and $13.1 \%$ crude fiber. The diet presented $25.7 \%$ of total dietary fiber $(1.6 \%$ soluble fiber and $23.5 \%$ insoluble fiber; composition by dry matter). The amount to feed was given following manufacturer's instructions and determined based on target weight. Weekly reviews of the dose were done to adjust the dose depending on the weight of the dog. No supplementations with other foods or treats were given during the treatment.

The variables measured were: body weight, $\mathrm{BCS}$, arterial blood pressure, heart rate and metabolic parameters (ALT, ALP, CLT, triglycerides and glucose) measured at the beginning (day 0) and at the end of the study (day 85).

Blood samples from all dogs were collected from the cephalic vein on day 0 and day 85 , at 10 a.m. after $12 \mathrm{hr}$ of withholding food. Blood was collected into heparinized tubes, and plasma was separated and analyzed within 30 min. Measurement was performed using the SPOTCHEM EZ SP-4430 auto-analyzer (Arkray, Inc., Kyoto, Japan).

Blood pressure and heart rate were assessed on days 0 and 85 , using an oscillometric method (Memoprint ${ }^{\circledR}, \mathrm{S}+\mathrm{B}$ medVET GmbH, Babenhausen, Germany) with an appropriately sized cuff placed around the front part of the left foreleg, medioproximal between the elbow and carpal joint, placing the sensor over radial artery, with the patient lying down upright in ventral recumbent position. Three measures were taken every $10 \mathrm{~min}$. Dogs were gently restrained and excluded from analysis, if they showed signs of stress. Hypertension was defined according to the criteria of the Veterinary Blood Pressure Society and the American College of Veterinary Internal Medicine (systolic blood pressure $\geq 150 \mathrm{~mm} \mathrm{Hg}$ and diastolic blood pressure $\geq 95 \mathrm{~mm} \mathrm{Hg}$ ) [5].

The SPSS statistical package (version 15.0. for Windows) was used throughout. Descriptive analyses of the variables were using the test of proportions for qualitative variables and measurements of central tendency (mean or median), measures of dispersion (standard deviation) for 
quantitative variables. For continuous variables, we used the Kolmogorov-Smirnov test to check that the variables were normally distributed. Normality was accepted at $P<0.05$. Comparison of absolute means between day 0 and day 85 was performed using Student's $t$-test, and comparison between the obtained differences in the parameters between both groups was performed by Student's $t$-test for independent samples.

All 36 dogs completed the study. There were no statistically significant differences between group A and group B regarding sex (82.4 vs. $84.2 \%$ males), mean age $(8.7 \pm 1.5$ vs. $10.3 \pm 2.0$ years $)$, mean initial body weight $(19.0 \pm 11.8$ vs. $15.8 \pm 9.5 \mathrm{~kg}$ ) and median initial body weight (14.00 vs. $11.25 \mathrm{~kg}$, respectively).

Of the 36 dogs included in the study, the BCS on day 0 was $8.47 \pm 0.53$ (median 8.00) and $7.79 \pm 0.41$ on day 85 (median 8.00 ). The global percentage of weight loss was 16.46 $\pm 6.81 \%$ and was not significant between group A (control) and group B (mitratapide), which was $16.8 \pm 8.0 \%$ and 16.1 $\pm 5.6 \%$, respectively. All the studied parameters decreased significantly after the loss of weight in both groups of dogs. Table 1 summarizes the mean values and percentages of reduction obtained in all measured parameters on day 0 and day 85 , in both groups of dogs.

There were no statistically significant differences in the initial values of all measured parameters between both groups, except for systolic blood pressure $(P=0.035)$ and diastolic blood pressure $(P<0.001)$. The mean systolic and diastolic blood pressures were above normal ranges for dogs on day 0 in both groups, decreasing to normal values at the end of the study. Furthermore, the percentage of decrease was statistically significant for diastolic blood pressure between both groups.

The levels of all measured metabolic parameters (ALT, ALP, CLT, triglycerides and glucose) decreased at the end of the treatment, being the triglycerides the higher percentage of decrease in the group B $(32.1 \pm 9.2 \%)$. The difference in the decrease between both groups was statistically significant for CLT and ALT $(P<0.05)$.

Mitratapide is indicated to be used as an aid in the management of overweight and obesity in adult dogs. Dobenecker et al. [9] showed that the treatment with mitratapide induces weight loss by reduction of fat tissue. In our study, all dogs finished the treatment, and in all cases, there was a significant loss of weight. Contrary to other studies, our results did not find a significant reduction of weight in the group of dogs treated with mitratapide when compared with the group of dogs treated only with diet [28]. This could be due to the fact that in these studies, the dogs were fed ad libitum for $3 \mathrm{hr}$ per day and do not specify the composition of the diet followed by the animals, while in our study, all dogs followed a low-fat high-fibre diet given appropriately to the weight of the dog in all cases. In fact, the discussed studies conclude that the obesity management programmer with mitratapide should be combined with individually adjusted dietary measures [28]. In the light of these results, following a properly adapted dietary programme, it seems that specific medical treatment with mitratapide is unnecessary for losing weight in dogs.

Several studies have documented that obesity has a detrimental effect on blood pressure in dogs and that obese dogs possess higher reference ranges of arterial pressure in contrast to normal weight dogs [3, 14, 20, 23]; also, concluded that weight status should be considered as a risk factor for the development of secondary hypertension $[5,20]$. In our study, the obese dogs showed systolic and diastolic blood pressures above normal ranges for dogs according to the Veterinary Blood Pressure Society and should be considered as animals under moderate to severe risk of target-organ damage [5].

At the end of the study, blood pressure values decreased in both groups of dogs, being within the normal ranges for dogs on day 85. In human subjects, obese hypertensive patients decrease blood pressure values to normal after loss of weight $[1,17,24]$, and some studies have also shown a significant decrease in arterial pressure in obese dogs after weight reduction $[22,23]$. In our study, the mean reduction on diastolic blood pressure was statistically significant in dogs from group $\mathrm{B}$ (mitratapide) compared with dogs from group A (control) $(P<0.001)$. Furthermore, in the interpretation of these results, it should be taken into consideration that average diastolic blood pressure was higher in group $\mathrm{B}$ on day 0 , and therefore, the percentage of reduction was greater in this group. However, on day 85, the mean diastolic blood pressures are within normal ranges in all animals, so we can assume that both ways of weight-loss programs succeeded in normalizing blood pressures. Regarding the heart rate, our results are similar to those of Bouthegourd et al. [4], who observed a decreased heart rate in overweight dogs after a weight loss program.

The effect of diet on metabolic parameters has not been reported extensively in dogs. Canine obesity is associated with high serum lipid levels and increased serum glucose, as well as ALT activity [4, 21, 23], whereas it has been reported a significant decrease in CLT and triglycerides levels after loss of weight with a specific diet $[4,8]$. Diez et al. [8] observed a decrease in serum cholesterol and triglycerides after feeding obese dogs with the same diet used in our study, although the differences were not significant. In our study, the obese dogs presented hyperlipidemia with CLT and triglycerides levels above the reference values for healthy dogs, whereas at the end of the study, we observed a statistically significant further decrease of triglycerides and CLT levels in dogs treated with mitratapide than in dogs only treated with a specific diet, which is to be expected and could be attributed to the properties of the mitratapide, so it might be considered a beneficial product for the treatment of the hyperlipidemia associated with the obesity in dogs [28].

Although the obese dogs of this study did not show hyperglycemia at the beginning of the treatment, a significant reduction of the levels of glucose was observed on day 85 in both groups of dogs. Although no statistically significant, the reduction of glucose values was higher in the dogs treated with mitratapide. The results suggest that loss of weight might help to improve diseases related to insulin resistance.

In the present study, a significant decrease of the activity of ALT and ALP at the end of the treatment was noticed, 
contrary to the study of Diez et al. [8], in which no effect was observed on these transaminases after the loss of weight. The reduction of ALT activity in dogs from group B (mitratapide) was statistically significant when compared to results from group A (control), although in both groups, mean values remained slightly above reference values.

Described side-effects of mitratapide are vomiting, diarrhea or softened stools, anorexia, lethargy or weakness, decrease in serum proteins, calcium and ALP, increase in ALT and aspartate aminotransferase, and occasional hyperkalemia [9]. In most cases, these effects are mild and transient. None of these side-effects was reported during the present study.

In conclusion, additionally to a low fat high fibre diet, the use of mitratapide in the treatment of the canine obesity does not seem to offer any additional useful effect in the loss of weight. On the other hand, mitratapide seems to present certain beneficial effects on pathologies associated to obesity, mainly related to blood pressure, lipids and hepatic parameters, although the efficacy of these is not clear and further studies should be carried out.

\section{REFERENCES}

1. Bautista-Castaño, I., Molina-Cabrillana, J., Montoya-Alonso, J. A. and Serra-Majem, L. 2003. Cardiovascular risk factors in overweight and obesity. Changes after a weight loss treatment. Med. Clin. (Barc.) 121: 485-491. [Medline]

2. Bland, I. M., Guthrie-Jones, A., Taylor, R. D. and Hill, J. 2009. Dog obesity: owner attitudes and behaviour. Prev. Vet. Med. 92: 333-340. [Medline] [CrossRef]

3. Bodey, A. R. and Michell, A. R. 1996. Epidemiological study of blood pressure in domestic dogs. J. Small Anim. Pract. 37: 116-125. [Medline] [CrossRef]

4. Bouthegourd, J. C., Kelly, M., Clety, N., Tardif, S. and Smeets, D. 2009. Effects of weight loss on heart rate normalization and increase in spontaneous activity in moderately exercised overweight dogs. Int. J. Appl. Res. Vet. Med. 7: 153-164.

5. Brown, S., Atkins, C., Bagley, R., Carr, A., Cowgill, L., Davidson, M., Egner, B., Elliott, J., Henik, R., Labato, M., Littman, M., Polzin, D., Ross, L., Snyder, P. and Stepien, R. 2007. Guidelines for the identification, evaluation, and management of systemic hypertension in dogs and cats. J. Vet. Intern. Med. 21: 542-558. [Medline] [CrossRef]

6. Colliard, L., Angel, J., Benet, J. J., Paragon, B. M. and Blanchard, G. 2006. Risk factors for obesity in dogs in France. J. Nutr. 136: 1951S-1954S. [Medline]

7. Courcier, E. A., Thomson, R. M., Mellor, D. J. and Yam, P. S. 2010. An epidemiological study of environmental factors associated with canine obesity. J. Small Anim. Pract. 51: 362-367. [Medline] [CrossRef]

8. Diez, M., Michaux, C., Jeusette, I., Baldwin, P., Istasse, L. and Biourge, V. 2004. Evolution of blood parameters during weight loss in experimental obese Beagle dogs. J. Anim. Physiol. Anim. Nutr. (Berl.) 88: 166-171. [Medline] [CrossRef]

9. Dobenecker, B., De Bock, M., Engelen, M., Goossensn, L., Scholz, A. and Kienzle, E. 2009. Effect of mitratapide on body composition, body measurements and glucose tolerance in obese Beagles. Vet. Res. Commun. 33: 839-847. [Medline] [CrossRef]

10. German, A. J. 2006. The growing problem of obesity in dogs and cats. J. Nutr. 136: 1940S-1946S. [Medline]

11. Gossellin, J., McKelvie, J., Sherington, J., Wren, J. A., Eagleson, J. S., Rowan, T. G. and Sunderland, S. J. 2007. An evaluation of dirlotapide to reduce body weight of client-owned dogs in two placebo-controlled clinical studies in Europe. J. Vet. Pharmacol. Ther. 30: 73-80. [Medline] [CrossRef]

12. Gossellin, J., Peachey, S., Sherington, J., Rowan, T. G. and Sunderland, S. J. 2007. Evaluation of dirlotapide for sustained weight loss in overweight Labrador retrievers. J. Vet. Pharmacol. Ther. 30 Suppl. 1: 55-65. [Medline] [CrossRef]

13. Gossellin, J., Wren, J. A. and Sunderland, S. J. 2007. Canine obesity: an overview. J. Vet. Pharmacol. Ther. 30: 1-10. [Medline] [CrossRef]

14. Joles, J. A. 1998. Obesity in dogs: Effects on renal function, blood pressure, and renal disease. Vet. Q. 20: 117-120. [Medline] [CrossRef]

15. Kusachi, K., Kamiya, F., Kogure, T., Hada, S., Chiba, N., Nakamura, M. and Arai, C. 1994. Investigation on obesity in dogs in the east Saitama area. Jpn. J. Small Anim. Pract. 13: 79-83.

16. Laflamme, D. P. 1997. Development and validation of a body condition score system for dogs. Canine Pract. 22: 10-15.

17. Masuo, K., Rakugi, H., Ogihara, T. and Lambert, G. W. 2012. Different mechanisms in weight loss-induced blood pressure reduction between a calorie-restricted diet and exercise. Hypertens. Res. 35: 41-47. [Medline] [CrossRef]

18. McGreevy, P. D., Thomson, P. C., Pride, C., Fawcett, A., Grassi, T. and Jones, B. 2005. Prevalence of obesity in dogs examined by Australian veterinary practices and the risk factors involved. Vet. Rec. 156: 695-702. [Medline]

19. Mertens, I. L. and Van Gaal, L. F. 2000. Overweight, obesity, and blood pressure: the effects of modest weight reduction. Obes. Res. 8: 270-278. [Medline] [CrossRef]

20. Montoya, J. A., Morris, P. J., Bautista, I., Juste, M. C., Suarez, L., Peña, C., Hackett, R. M. and Rawlings, J. 2006. Hypertension: a risk factor associated with weight status in dogs. J. Nutr. 136: 2011S-2013S. [Medline]

21. Peña, C., Suárez, L., Bautista, I., Montoya, J. A. and Juste, M. C. 2008. Relationship between analytic values and canine obesity. J. Anim. Physiol. Anim. Nutr. (Berl.) 92: 324-325. [Medline] [CrossRef]

22. Neto, G. B. P., Brunetto, M. A., Sousa, M. G., Carciofi, A. C. and Camacho, A. A. 2012. Effects of weight loss on the cardiac parameters of obese dogs. Pesqui. Vet. Bras. 30: 167-171. [CrossRef]

23. Rocchini, A. P., Moorehead, C., Wentz, E. and Deremer, S. 1987. Obesity-induced hypertension in the dog. Hypertension 9: III64-68. [Medline] [CrossRef]

24. Smith, P. J., Blumenthal, J. A., Babyak, M. A., Craighead, L., Welsh-Bohmer, K. A., Browndyke, J. N., Strauman, T. A. and Sherwood, A. 2010. Effects of the dietary approaches to stop hypertension diet, exercise, and caloric restriction on neurocognition in overweight adults with high blood pressure. Hypertension 55: 1331-1338. [Medline] [CrossRef]

25. Suarez, L., Peña, C., Carretón, E., Juste, M. C., Bautista-Castaño, I. and Montoya-Alonso, J. A. 2012. Preferences of owners of overweight dogs when buying commercial pet food. J. Anim. Physiol. Anim. Nutr. (Berl.) 96: 655-659. [Medline] [CrossRef]

26. Swinburn, B. A., Sacks, G., Hall, K. D., McPherson, K., Finegood, D. T., Moodie, M. L. and Gortmaker, S. L. 2011. The global obesity pandemic: shaped by global drivers and local environments. Lancet 378: 804-814. [Medline] [CrossRef]

27. Wren, J. A., King, V. L., Campbell, S. L. and Hickman, M. A. 2007. Biologic activity of dirlotapide, a novel microsomal triglyceride transfer protein inhibitor, for weight loss in obese dogs. $J$. Vet. Pharmacol. Ther. 30 Suppl. 1: 33-42. [Medline] [CrossRef]

28. Yarvitan. Scientific Discussion. 2008. In: European Medicines Agency (EMEA). (EPAR, ed.), Available from http://www.ema. europa.eu. 